\title{
Die Aufwachphase nach der tiefen Narkose
}

\section{Ueli Bollag}

Dr. med., Facharzt für Kinder- und Jugendmedizin

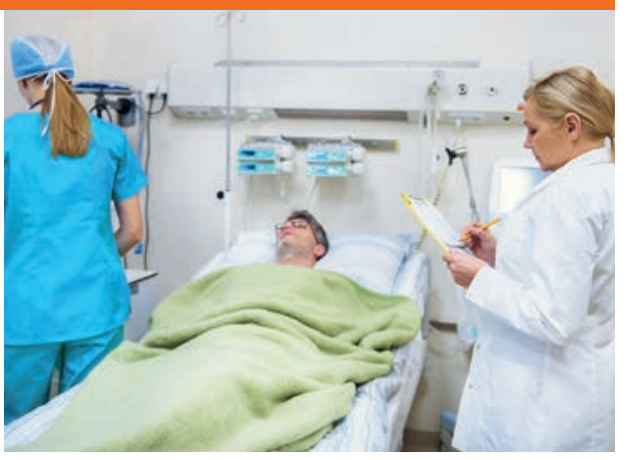

Betreuung im Aufwachraum (Symbolbild). (C) Gpointstudio | Dreamstime.com
Bei gewissen Bewegungen, z.B. Aussteigen aus dem Auto oder Aufsteigen aufs Velo, zwickte mich die in den linken Femurhals versenkte Schraube. Über das Drum und Dran sowie schliesslich die Operation im Hôpital de Béziers habe ich berichtet [1]. Doch nun soll das Metall raus, das mich stört, ambulant, aber in Vollnarkose.

Da lag ich nun im Aufwachsaal, leicht wie ein Federchen, wohlig war mir wie einer schnurrenden Katze. Ich vernahm das Getrippel von Leuten rundherum und entfernte Stimmen. Ich wähnte mich aus dem Jenseits erwachend und doch noch weit weg vom Leben. Wohl gebettet, inmitten von anderen Körpern, die aus der Narkose erwachten, träumte ich vor mich hin.

«Was sind wir doch für privilegierte Menschen, dürfen umsorgt von Schwestern und Pflegern in sauberen weissen Decken ruhen. Im Jemen etwa, wo die Ärmsten der Armen von sich um die Macht balgenden Truppen zum Frieren, Hungern und Sterben gezwungen werden, die Kleinsten unter ihnen wehrlos, die Kinder. Oder die Menschen, die auf gefährlichen Wegen aus Armut fliehen und hoffen, irgendwo in der weiten Welt ein schöneres Leben zu finden, Arbeit und Auskommen. Von üblen Schleppern werden sie ihres ganzen Hab und Guts beraubt, oft misshandelt und sexuell genötigt. Oder die staatenlosen Rohingyas, sunnitische Muslime in Myanmar, die, unter Repression und Verfolgung darbend, aus ihren brennenden Hütten in Richtung Bangladesch fliehen, um dem Tod zu entkommen. Dort versuchen sie zu überleben, in riesigen Lagern, im Monsunregen watend, notdürftig untergebracht in Zelten und selbst gezimmerten Räumen. Wo führen uns machtgierige Politiker, Populisten und Allahu Akbar schreiende Mörder hin, allen voran

Tel. +33 (0) 467246477 u.bollag[at]bluewin.ch ein Präsident der Vereinigten Staaten von Amerika, der bisher ungestraft twittern, lügen und richten darf. Verblendete Typen an der Spitze vieler Staaten: Ungarn, Italien, Polen, Nicaragua, Türkei und andere Länder. Auch die kriegerischen Auseinandersetzungen zwischen Russland und der Ukraine sind noch nicht ausgestanden. In vielen afrikanischen Staaten brodelt es, und immer wieder kommt es zu Übergriffen auf unschuldige Menschen.»

Plötzlich fühle ich mich umgeben von Erdmännchen und Feen, die an mir herumbasteln. Ein angenehmer Druck auf meinem linken Oberschenkel lässt mich

Was sind wir doch für privilegierte Menschen, dürfen umsorgt von Schwestern und Pflegern in sauberen weissen Decken ruhen.

weiter erwachen. Ganz offensichtlich hat's zu bluten begonnen, ein umfangreiches Hämatom hat sich gebildet. Noch bin ich beduselt, kann jetzt aber die Uhr an der gegenüberliegenden Wand entziffern. Was, so lange soll diese Operation gedauert haben? Natürlich nicht. Man hat mich etwas gar tief versenkt. Aber das Aufwachen geht sanft voran, keine Schmerzen, nur einen dicken Verband um den linken Oberschenkel. $\mathrm{Ab}$ geht's aufs Zimmer, wo ich auf den Besuch des Chirurgen warten muss. Wenn ich nur wieder nach Hause gehen darf mit diesem dicken Oberschenkel. Überlassen Sie's mir, bitte, ich kann mich selbst versorgen, will raus aus dem Spital.

Heute, Monate nach der Entnahme des Implantats, bin ich wieder der Alte, eben der Alte. Die Muskulatur im linken Oberschenkel hat arg gelitten, wahrscheinlich wegen der Nachblutung. Darum Training auf dem Velo, Quadrizeps-Übungen am Morgen und häufiges Treppensteigen. Der Unfall auf dem Mont Ventoux ist abgehakt. Unvergessen die Zeit im Aufwachsaal, die vielen Gedanken, die mein Gehirn im Halbschlaf durchfluteten, das Gefühl, dem ewigen Erlöschen nahe gewesen zu sein.

\section{Literatur}

1 Bollag U. Medizinische Betreuung à la française. Schweiz Ärzteztg. 2017;98(45):1518-9. 